\title{
Crescimento de pimentão em diferentes arranjos espaciais
}

\author{
Paulo Igor Barbosa e Silva(1), Maria Zuleide de Negreiros $^{(2)}$, Karidja Kalliany Carlos de Freitas Moura ${ }^{(3)}$, \\ Francisco Cláudio Lopes de Freitas ${ }^{(2)}$, Glauber Henrique de Sousa Nunes ${ }^{(2)}$, \\ Paulo Sérgio Lima e Silva ${ }^{(2)}$ e Leilson Costa Grangeiro ${ }^{(2)}$
}

\begin{abstract}
(1)Universidade Federal de Viçosa, Departamento de Fitotecnia, Avenida P.H. Rolfs, s/no, CEP $36570-000$ Viçosa, MG. E-mail: pauloigorbs@hotmail.com (2)Universidade Federal Rural do Semi-Árido, Departamento de Ciências Vegetais, Rodovia BR 110, Km 47, s/no , Presidente Costa e Silva, CEP 59625-900 Mossoró, RN. E-mail: zuleide@ufersa.edu.br, franciscoclaudio@ufersa.edu.br, glauber@ufersa.edu.br, paulosergio@ufersa.edu.br, leilson@ufersa.edu.br (3)Rua Irene Carlos de Paiva, no 197, Nova Betânia, CEP $59612-635$ Mossoró, RN. E-mail: karidja@ig.com.br
\end{abstract}

Resumo - O objetivo deste trabalho foi avaliar o crescimento do pimentão cv. Atlantis sob diferentes arranjos espaciais. Foram avaliados três arranjos de espaçamentos entre fileiras duplas e fileiras simples de plantio $(1,5 \times 0,5,1,6 \times 0,4$ e $1,7 \times 0,3 \mathrm{~m})$, e quatro espaçamentos entre plantas nas fileiras $(0,2,0,3,0,4$ e $0,5 \mathrm{~m})$, combinados em esquema fatorial. Utilizou-se o delineamento de blocos ao acaso, com três repetições e parcelas subdivididas no tempo. A avaliação de crescimento foi realizada em nove épocas espaçadas em 14 dias, com a primeira avaliação realizada 14 dias após o transplantio (DAT). Até os 126 DAT, foram avaliados: área foliar (AF); índice de área foliar (IAF); massas secas de folhas (MSF), do caule (MSC), de frutos (MSFr) e do total da parte aérea (MST); taxa de crescimento absoluto (TCA), assimilatória líquida (TAL) e de crescimento relativo (TCR); e as razões de área foliar (RAF) e de massa foliar (RMF). As alterações em AF, TCR, RMF e RAF foram independentes do espaçamento entre fileiras que, no entanto, influenciou MSF, MSC, MSFr e MST, IAF e TCA. O aumento do espaçamento entre plantas reduz o IAF e a RAF e aumenta a AF, MSF, MSC, MSFr, MST, TCA e TAL, mas não influencia a TCR e RMF.

Termos para indexação: Capsicum annuum, acúmulo de massa seca, análise de crescimento, densidade de plantio.

\section{Growth of green pepper in different spatial arrangements}

\begin{abstract}
The objective of this work was to evaluate the growth of green pepper cv. Atlantis under different spatial arrangements. Three spacing arrangements between double and simple planting rows $(1.5 \times 0.5 \mathrm{~m}$, $1.6 \times 0.4 \mathrm{~m}$ and $1.7 \times 0.3 \mathrm{~m})$ and four spacing distances between plants in the rows $(0.2,0.3,0.4$ and $0.5 \mathrm{~m})$ combined in factorial scheme were evaluated. A randomized block design in split-plots divided in time with three replicates was used. The growth assessment was done in nine occasions, 14 days apart, and the first one was performed 14 days after transplanting (DAT). Leaf area (LA), leaf area index (LAI), dry masses of leaves (LDM), stem (SDM), fruit (FrDM) and total shoot (TDM); absolute growth rate (AGR), rates of net assimilation (NAR) and relative growth (RGR); and leaf area (LAR) and leaf mass (LWR) ratios were evaluated until 126 DAT. The changes in LA, RGR, LWR and LAR did not depend on row spacing, but spacing influenced LDM, SDM, FrDM and TDM, LAI and AGR. The increase in spacing reduces LAI and LAR, and increases LA, LDM, SDM, FrDM, TDM, AGR and NAR, but does not influence RGR and LWR.
\end{abstract}

Index terms: Capsicum annuum, accumulation of dry mass, growth analysis, planting density.

\section{Introdução}

Adensidade de plantio é um dos principais fatores que influenciam o rendimento das culturas (López-Bellido et al., 2005), inclusive a do pimentão (Jolliffe \& Gaye, 1995). A densidade de plantio está associada à competição intraespecífica por luz, água e nutrientes. Outro aspecto associado à densidade de plantio é o arranjo das plantas no campo, isto é, a distribuição espacial das plantas na área de plantio. Estudos relacionados à densidade de plantio com o intuito de alterar as características agronômicas e fisiológicas são raros em pimentão (Capsicum annuum). Kahn et al. (1997) verificaram aumentos nas massas das matérias fresca e seca das raízes e da parte aérea de pimentão, por planta, com o aumento do espaçamento entre plantas na fileira. Jolliffe \& Gaye (1995) observaram que o aumento da densidade de plantio reduz área foliar, massa da matéria seca de folhas e da parte aérea e taxa de crescimento absoluto das plantas de pimentão. Aumentos na produção e reduções na massa média de frutos têm sido observados em tomate (Streck

Pesq. agropec. bras., Brasília, v.45, n.2, p.132-139, fev. 2010 
et al., 1998; Machado et al., 2007) e melão (Pereira et al., 2003; Chaves et al., 2004) sob alta densidade de plantio. Decoteau \& Graham (1994) mostraram efeitos do arranjo espacial sobre o rendimento e a distribuição dos frutos em plantas de Capsicum spp. quando usaram uma mesma densidade de plantio.

A análise de crescimento é um método de grande utilidade para a avaliação das diferenças no comportamento de cultivares influenciadas por práticas agronômicas, efeitos de competição ou climáticos, e por fatores intrínsecos associados à fisiologia da planta (Andrade et al., 2005; Guimarães et al., 2008).

Os princípios e as práticas da análise de crescimento têm como objetivo descrever e interpretar o desempenho de determinada espécie em ambiente natural ou controlado (Benincasa, 2003). Normalmente, a mensuração sequencial do acúmulo de matéria orgânica, considerando-se a massa das partes secas da planta (frutos, caule, folhas e outros), é o fundamento da análise de crescimento (Fontes et al., 2005). No entanto, vários índices fisiológicos também são utilizados nessa análise, como índice de área foliar, taxas de crescimento da cultura, de crescimento relativo e de assimilação líquida (Fontes et al., 2005; Pôrto et al., 2005; Costa et al., 2006; Monte et al., 2009).

Por meio da análise de crescimento do pimentão, Jolliffe \& Gaye (1995) determinaram que o número de nós da planta é o principal componente do rendimento de frutos. Com o avanço na idade da planta, Fontes et al. (2005) observaram que o aumento na massa de matéria seca de folhas vivas e de frutos do pimentão pode ser descrito por equações lineares, e o aumento na massa de matéria seca de folhas senescentes do total de folhas e do caule, por equações quadráticas. Esses autores observaram também que o aumento na área foliar das plantas foi descrito por equação cúbica, e que a taxa de crescimento absoluto e a massa da matéria seca total são descritas por equações do tipo raiz quadrática.

O objetivo deste trabalho foi avaliar o crescimento do pimentão cv. Atlantis sob diferentes arranjos espaciais.

\section{Material e Métodos}

O trabalho foi realizado no período de julho a novembro de 2006, na empresa W.G. Fruticultura, sediada no Sítio Sumidoro, localizado na zona rural do Município de Baraúnas, RN $\left(5^{\circ} 05^{\prime} \mathrm{S}\right.$, $37^{\circ} 38^{\prime}, 95 \mathrm{~m}$ de altitude). A análise do solo da área experimental, classificado como Argissolo Vermelho-Amarelo (Santos et al., 2006), apresentou: $\mathrm{pH}\left(\mathrm{CaCl}_{2}\right), 7,2 ; \mathrm{Ca}, 9,1 \mathrm{cmol}_{\mathrm{c}} \mathrm{dm}^{-3} ; \mathrm{Mg}, 2,3 \mathrm{cmol}_{\mathrm{c}} \mathrm{dm}^{-3}$; $\mathrm{K}, 0,83 \mathrm{cmol}_{\mathrm{c}} \mathrm{dm}^{-3} ; \mathrm{Al}, 0,00 \mathrm{cmol}_{\mathrm{c}} \mathrm{dm}^{-3} ; \mathrm{P}, 53 \mathrm{mg} \mathrm{dm}^{-3}$; e matéria orgânica, $17 \mathrm{~g} \mathrm{dm}^{-3}$.

Utilizou-se o delineamento de blocos completos ao acaso, em esquema fatorial $3 \times 4$, com três repetições. Foram avaliados três arranjos de espaçamentos entre fileiras duplas e simples de plantio $(1,5 \times 0,5,1,6 \times 0,4$ e $1,7 \times 0,3 \mathrm{~m})$, além de quatro espaçamentos entre plantas nas fileiras $(0,2,0,3,0,4$ e $0,5 \mathrm{~m})$. Como o comprimento total dos diferentes arranjos de espaçamentos entrefileiras duplas e simples foi sempre igual a $2 \mathrm{~m}(1,5+0,5 ; 1,6+0,4$; $1,7+0,3 \mathrm{~m}$ ), as densidades de plantio variaram de acordo com o espaçamento entre plantas nas fileiras: 50.000, 33.333, 25.000 e 20.000 plantas $\mathrm{ha}^{-1}$, respectivamente. Cada parcela experimental foi constituída por oito fileiras de plantas, com 7,6 m de comprimento. Como área útil, considerou-se a área ocupada pelas duas fileiras duplas centrais, eliminando-se uma cova nas extremidades de cada fileira.

O preparo do solo consistiu de uma aração e uma gradagem e de sulcamento com profundidade aproximada de $0,15 \mathrm{~m}$ nas linhas de plantio. A semeadura foi realizada em 18/7/2006, em bandejas de poliestireno expandido com 200 células preenchidas com substrato comercial Golden Mix (Amafibra Fibras e Substratos Agrícolas da Amazônia Ltda., Holambra, SP), utilizando-se o híbrido Atlantis. Esse híbrido é adaptado às condições de campo e estufas e apresenta alto potencial produtivo de frutos, com ciclo médio de 120 dias. As mudas foram transplantadas 30 dias após a semeadura, quando apresentavam de dois a três pares de folhas definitivas.

A cultura foi irrigada por gotejamento, com emissores de vazão de $1,3 \mathrm{~L} \mathrm{~h}^{-1}$, e a quantidade de água necessária para irrigação foi estimada de acordo com a evapotranspiração da cultura (Allen et al., 1998). A adubação foi realizada por fertirrigação, com uso de ureia (75\% do $\mathrm{N}$ total aplicado) e ácido nítrico como fontes de nitrogênio; ácido fosfórico como fonte de $\mathrm{P}$; cloreto de potássio ( $32 \%$ de $\mathrm{K}$ ) e sulfato de potássio $(68 \%$ de $\mathrm{K})$ como fontes de $\mathrm{K}$, tendo-se aplicado o cloreto de potássio até 50 DAT e o sulfato de potássio a partir dessa data até o fim do experimento. $\mathrm{O}$ enxofre aplicado foi proveniente do sulfato de 
potássio e do sulfato de magnésio a $76 \%$ e $24 \%$, respectivamente. A fonte de magnésio foi o sulfato de magnésio. Durante o experimento, foram aplicados $215,65,314,90$ e $15 \mathrm{~kg} \mathrm{ha}^{-1}$ de $\mathrm{N}, \mathrm{P}_{2} \mathrm{O}_{5}, \mathrm{~K}_{2} \mathrm{O}$, S e $\mathrm{Mg}$, respectivamente. As práticas culturais foram constituídas por capinas manuais, pulverizações com fungicidas e inseticidas, e tutoramento para condução das plantas.

A análise de crescimento foi feita com dados de nove épocas de avaliação $(14,28,42,56,70,84,98$, 112 e 126 DAT), pela coleta aleatória de uma planta competitiva por parcela, sendo que na primeira coleta foram colhidas duas plantas. As plantas amostradas foram cortadas rentes ao solo e divididas em caule, folhas e frutos. As folhas foram destacadas das hastes, o limbo foliar foi separado do pecíolo e a área foliar foi medida eletronicamente com uso de medidor modelo LI-3100 e Li-Cor Biosciences, (Lincoln, NE, EUA). Os frutos foram colhidos ao atingir o ponto de consumo imaturo (verdes). As folhas, hastes e os frutos foram secos em estufa com circulação forçada de ar, regulada à temperatura de $65^{\circ} \mathrm{C}$, até atingir massa constante. Para cada época de avaliação, foram determinados: área foliar (AF, $\mathrm{m}^{2}$ planta $\left.^{-1}\right)$, índice de área foliar (IAF), massa seca de folhas (MSF, g planta ${ }^{-1}$ ), massa seca de caule (MSC, g planta ${ }^{-1}$ ), massa seca de frutos (MSFr, g planta ${ }^{-1}$ ), massa seca total (MST, g planta ${ }^{-1}$ ), razão de área foliar (RAF, $\mathrm{m}^{2} \mathrm{~g}^{-1}$ ) e razão de massa foliar $\left(\mathrm{RMF}, \mathrm{gm}^{-2}\right)$. Nos intervalos compreendidos entre duas avaliações, foram obtidas as taxas de crescimento absoluto (TCA, g planta ${ }^{-1}$ dia $^{-1}$ ), relativo (TCR, $\mathrm{g} \mathrm{g}^{-1} \mathrm{dia}^{-1}$ ) e assimilatória líquida (TAL, $\mathrm{g} \mathrm{m}^{-2} \mathrm{dia}^{-1}$ ), conforme Benincasa (2003).

Os dados foram submetidos às análises de variância e de regressão, com uso dos softwares SAEG (Ribeiro Júnior, 2001) e Table Curve (Jandel, 1992), respectivamente. Os modelos de regressão foram escolhidos com base na significância dos coeficientes de regressão, testados pelo teste $\mathrm{t}$ a 1,5 e $10 \%$ de probabilidade, e também de acordo com os coeficientes de determinação e a resposta biológica das características em estudo.

\section{Resultados e Discussão}

Não foram observados efeitos das interações entre o espaçamento entre fileiras e a densidade de plantas (espaçamento entre plantas nas fileiras) em nenhuma das épocas de avaliação utilizadas. Não foram observados, também, efeitos dos diferentes arranjos espaciais entre fileiras sobre as características avaliadas. É possível que os grandes espaçamentos entre fileiras duplas, bem como a relação inversa utilizada entre distâncias das fileiras duplas $(1,5,1,6$ ou $1,7 \mathrm{~m})$ e fileiras simples $(0,5,0,4$ ou $0,3 \mathrm{~m})$ tenham anulado ou reduzido muito a competição entre plantas e contribuído para a ausência de efeitos dos diferentes arranjos espaciais. Decoteau \& Graham (1994) verificaram ausência de efeitos significativos dos mesmos arranjos espaciais entre fileiras de plantio utilizados neste trabalho sobre o rendimento da pimenta Cayenne cultivada.

Foram observados efeitos significativos das densidades de plantio (espaçamento nas fileiras, E) e das épocas de avaliação (EA) sobre a área foliar, mas não da interação E x EA. A área foliar aumentou até os 112 DAT e, depois disso, tendeu a se estabilizar nos espaçamentos entre plantas nas fileiras de 0,4 (E3) e 0,2 m (E1), e a diminuir nos espaçamentos de 0,3 (E2) e 0,5 m (E4) (Figura 1 A). A área foliar por planta aumentou com o aumento do espaçamento entre plantas na fileira, o que está de acordo com os resultados obtidos por outros autores (Jolliffe \& Gaye, 1995). O espaçamento maior reduz a competição entre plantas por água, nutrientes e luz, e propicia a formação de maior número de folhas, bem como de folhas maiores.

Constatou-se efeito das densidades de plantio (espaçamentos entre plantas nas fileiras, E), das épocas de avaliação (EA) e da interação E x EA sobre o IAF e as massas de matéria seca de folhas, do caule, dos frutos e total da parte aérea. O IAF aumentou com o avanço da idade das plantas nos quatro espaçamentos, e as menores densidades de plantio (maiores espaçamentos nas linhas) resultaram em decréscimos no IAF (Figura $1 \mathrm{~B}$ ) em razão da diminuição do número de plantas por unidade de área. $\mathrm{O}$ aumento foi contínuo, com tendência de crescimento mais lento a partir dos 98 DAT. Resultados semelhantes foram verificados por Fontes et al. (2005).

A massa de matéria seca de folhas aumentou continuamente com o aumento da idade das plantas em todos os tratamentos (Figura $1 \mathrm{C}$ ). $\mathrm{O}$ efeito do espaçamento sobre essa característica começou a manifestar-se no período de 70 a 84 DAT. A massa de matéria seca de folhas por planta aumentou com a redução da densidade de plantio (aumento em E) em

Pesq. agropec. bras., Brasília, v.45, n.2, p.132-139, fev. 2010 
razão da menor competição entre plantas, o que está de acordo com o observado por outros autores (Jolliffe \& Gaye, 1995; Motsenbocker, 1996).
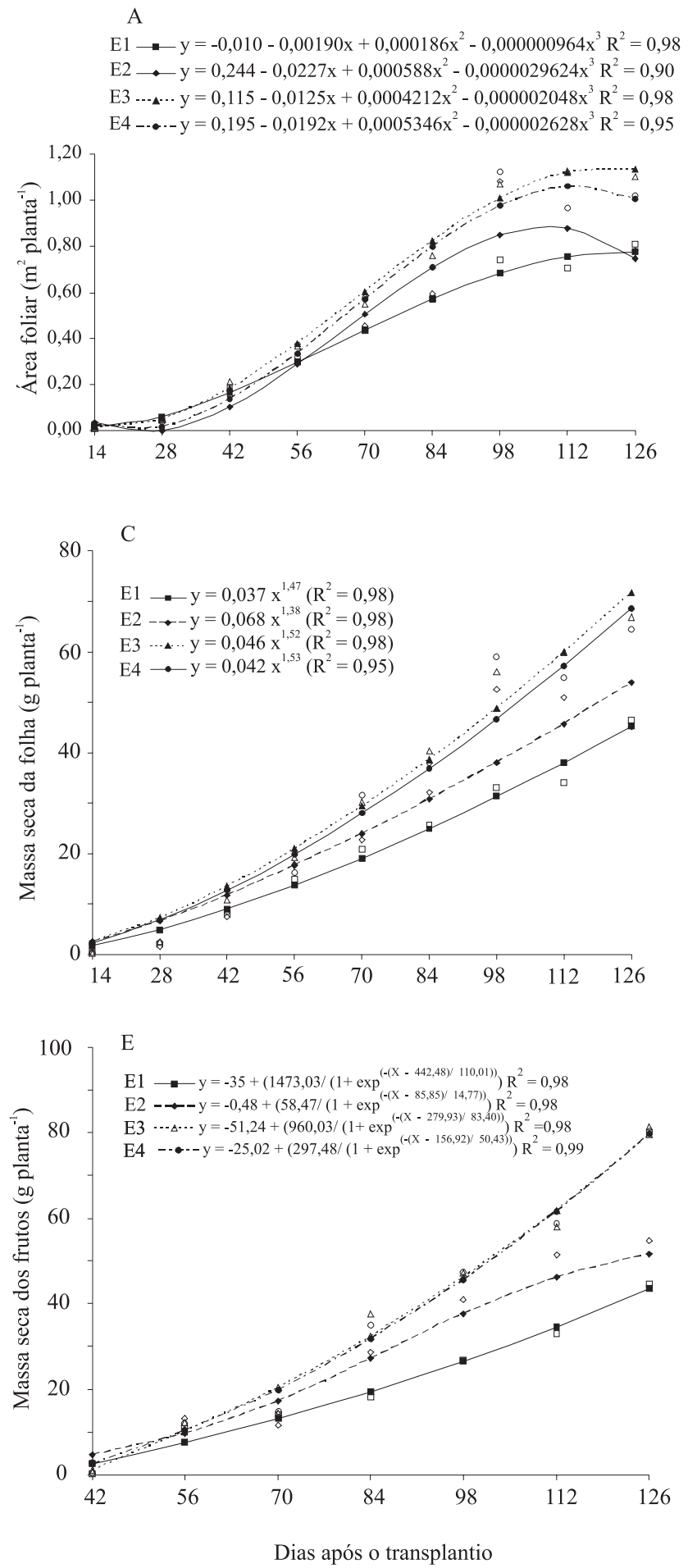

A massa de matéria seca do caule das plantas de pimentão apresentou aumento contínuo durante todo o período de avaliação (Figura 1 D). A partir dos
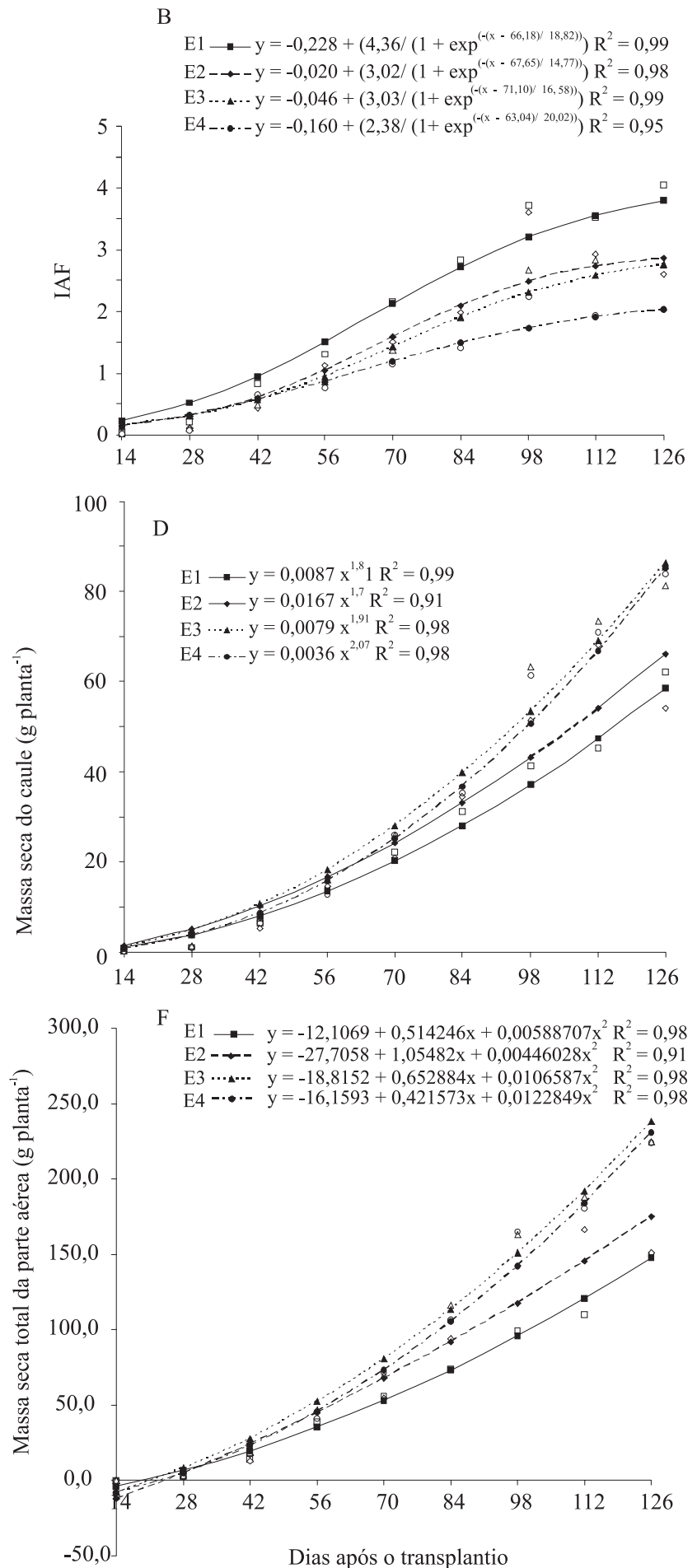

Figura 1. Área foliar (A), índice de área foliar (B), massas de matéria seca de folhas (C), caule (D), frutos (E) e total da parte aérea (F) do pimentão cv. Atlantis, em função dos dias após o transplantio, em resposta ao espaçamento entre plantas na fileira. E1, 0,2 m; E2, 0,3 m; E3, 0,4 m; e E4, 0,5 m. 
98 DAT, as menores densidades de plantio (E de 0,4 e $0,5 \mathrm{~m}$ ) proporcionaram maior massa de matéria seca do caule em relação às maiores densidades ( $\mathrm{E}$ de 0,2 e $0,3 \mathrm{~m})$.

A massa de matéria seca de frutos aumentou com a idade das plantas e com o aumento do espaçamento entre plantas na fileira (Figura $1 \mathrm{E}$ ). Fontes et al. (2005) verificaram aumentos lineares da massa de matéria seca de frutos em função da idade da planta. Jolliffe \& Gaye (1995) verificaram aumento da massa de matéria seca de frutos quando a densidade de plantio foi reduzida de 11,1 para 1,4 plantas $\mathrm{m}^{-2}$.

Amassa de matéria seca total (folhas + caule + frutos) do pimentão também aumentou continuamente durante o período experimental considerado (Figura 1 F). O aumento do espaçamento reduziu a competição entre plantas e determinou maiores massas de matéria seca de folhas, caule e de frutos e, consequentemente, maior massa de matéria seca total da parte aérea.

A razão de área foliar (RAF) foi reduzida com a idade da planta e como aumento do espaçamento entre plantas (Figura 2 A). Diminuição da RAF ao longo do ciclo da cultura indica decréscimo na quantidade de assimilados destinados às folhas na medida em que elas envelhecem, o que, consequentemente, ocasiona redução na taxa de crescimento relativo (Fontes et al., 2005). Em outras culturas, a RAF não foi influenciada pela densidade de plantio (Jauer et al., 2003). Provavelmente, a competição entre as partes da planta por carboidratos torna-se progressivamente maior com o passar do tempo nos maiores espaçamentos, especialmente após formação dos frutos, o que reduz a RAF.

A razão de massa foliar (RMF) foi influenciada apenas pela época de amostragem. A RMF diminuiu com o aumento da idade das plantas (Figura 2 B) de modo praticamente igual nos quatro espaçamentos entre plantas nas fileiras. Essa diminuição na RMF é uma observação frequente nas análises de crescimento do pimentão (Fontes et al., 2005) e outras culturas (Jauer et al., 2003). Esse decréscimo é esperado porque a proporção de folhas na matéria seca total diminui em razão da formação de ramos e, posteriormente, de flores e frutos.

A taxa de crescimento absoluto (TCA) foi influenciada pelo espaçamento entre plantas nas linhas (E), época de amostragem (EA) e pela interação E x EA. A TCA aumentou com a idade da planta e com o aumento do espaçamento (Figura $2 \mathrm{C}$ ), o que está de acordo com Fontes et al. (2005).

A taxa de crescimento relativo (TCR) foi maior aos 28 dias após o transplantio (DAT), com maior valor para o espaçamento de $0,4 \mathrm{~m}$ entre plantas (E3), declinou progressivamente até os 84 DAT e, a partir daí, manteve-se estável até o fim do período de observação (Figura 2 D). Decréscimos nos valores de TCR ao longo do ciclo da cultura são comuns para a maioria das espécies, inclusive no pimentão, e estão relacionados aos decréscimos na taxa assimilatória líquida e na razão de área foliar. Com o aumento da massa acumulada pela planta, ocorre aumento da necessidade de fotoassimilados para a manutenção dos órgãos já formados (folhas, hastes, flores e frutos). Assim, a quantidade de fotoassimilados disponível para o crescimento (TCR) tende a ser menor (Benincasa, 2003). A redução da TCR com o avanço na idade do ciclo das plantas possivelmente decorre do autossombreamento e da produção de órgãos não fotossintetizantes (Jauer et al., 2003), mas é provável que o sombreamento mútuo e a senescência foliar também estejam envolvidos. Fontes et al. (2005) observaram que a TCR diminui com a idade do pimentão. Por outro lado, Jauer et al. (2003) verificaram relação inversa entre a TCR e a densidade de plantio. Além da cultura avaliada por esses autores ter sido outra, as densidades de plantio usadas foram bem mais elevadas do que as avaliadas no presente trabalho, o que pode explicar a discordância. Altas densidades de plantio representam condição estressante, e essas condições reduzem a TCR (Turner \& Wien, 1994).

Houve efeito de espaçamentos (E) e de épocas de avaliação (EA), mas não da interação E x EA sobre a taxa assimilatória líquida (TAL). A TAL diminuiu em função da idade das plantas a partir dos 28 DAT, o que mostra uma tendência de estabilização nos últimos DAT (Figura 2 E). No presente trabalho, a obtenção de um valor máximo de TAL e o posterior declínio descritos por Fontes et al. (2005) não foram observados, o que está de acordo com o comportamento dessa variável observado por Jauer et al. (2003). O aumento do espaçamento aumentou a TAL, o que também está de acordo com os dados observados por Jauer et al. (2003). 

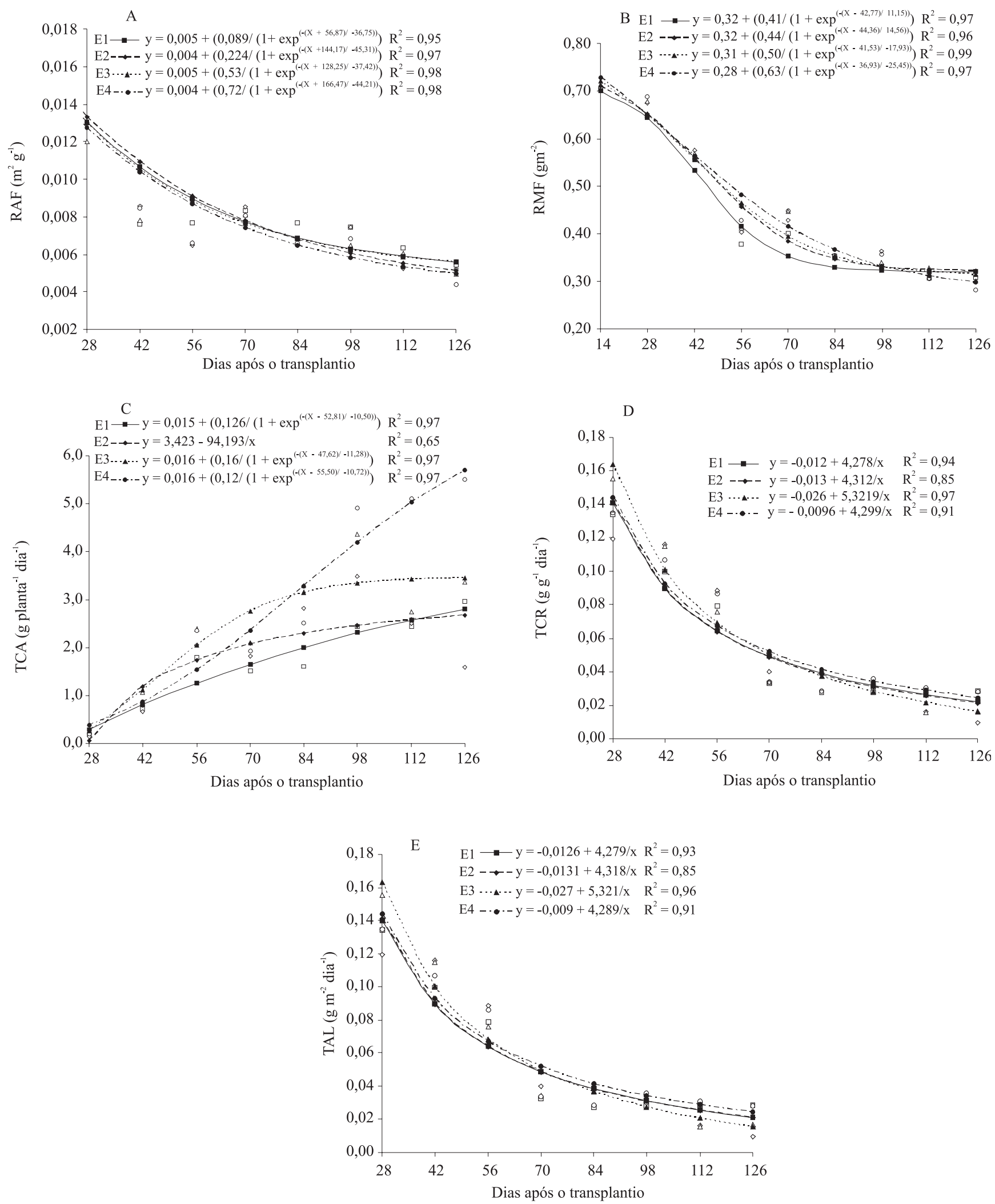

Figura 2. Razões de área foliar (A) e de massa foliar (B), taxa de crescimento absoluto (C), taxa de crescimento relativo (D) e taxa assimilatória líquida (E) do pimentão cv. Atlantis, em função dos dias após o transplantio, em resposta ao espaçamento entre plantas nas fileiras. E1, 0,2 m; E2, 0,3 m; E3, 0,4 m; e E4, 0,5 m. 


\section{Conclusões}

1. Os arranjos do espaçamento entre fileiras duplas e simples testados não influenciam as características de crescimento do pimentão.

2. Na cultivar de pimentão Atlantis, há aumento da área foliar, do índice de área foliar, das massas de matéria seca de folhas, caule, frutos e total da parte aérea e da taxa de crescimento absoluto, e redução da taxa assimilatória líquida, das taxas de crescimento relativo e das razões da área foliar e de massa foliar até os 126 dias após o transplantio.

3. As alterações em área foliar, taxa de crescimento relativo e razões de massa foliar e de área foliar são independentes dos arranjos de espaçamento entre fileiras de plantio da cv. de pimentão Atlantis, e as alterações nas massas de matéria seca de folhas, caule, frutos e total da parte aérea, nos índices de área foliar e nas taxas de crescimento absoluto são influenciadas pela densidade de plantio.

4. A redução na densidade de plantio em pimentão da cv. Atlantis reduz o índice de área foliar e a razão de área foliar e aumenta a área foliar, as massas de matéria seca foliar, de caule, de frutos e total da parte aérea, além da taxa assimilatória líquida, e não influencia a taxa de crescimento relativo e a razão de massa foliar.

\section{Referências}

ALlEN, R.G.; PEREIRA, L.S.; RAES, D.; SMITH, M. Crop evapotranspiration: guidelines for computing crop water requirements. Rome: FAO, 1998. 279p. (FAO. Irrigation and drainage paper, 56).

ANDRADE, A.C.; FONSECA, D.M. da; LOPES, R. dos S.; NASCIMENTO JÚNIOR, D. do; CECON, P.R.; QUEIROZ, D.S.; PEREIRA, D.H.; REIS, S.T. Análise de crescimento do capim-elefante 'Napier' adubado e irrigado. Ciência e Agrotecnologia, v.29, p.415-423, 2005.

BENINCASA, M.M.P. Análise de crescimento de plantas: noções básicas. 2.ed. Jaboticabal: Funep, 2003. 41p.

CHAVES, S.W.P.; NEGREIROS, M.Z. de; NOGUEIRA, I.C.C.; PEDROSA, J.F.; BEZERRA NETO, F.; PEREIRA, F.H.F. Densidade de plantio na produção e qualidade de frutos em híbridos de melão. Revista Caatinga, v.17, p.39-45, 2004.

COSTA, C.C.; OLIVEIRA, C.D. de; SILVA, C.J. da; TIMOSSI, P.C.; LEITE, I.C. Crescimento, produtividade e qualidade de raízes de rabanete cultivadas sob diferentes fontes e doses de adubos orgânicos. Horticultura Brasileira, v.24, p.118-122, 2006.

DECOTEAU, D.R.; GRAHAM,H.A.H.Plant spatial arrangement affects growth, yield, and pod distribution of Cayenne peppers. HortScience, v.29, p.149-151, 1994.
FONTES, P.C.R.; DIAS, E.N.; SILVA, D.J.H. da. Dinâmica do crescimento, distribuição de matéria seca e produção de pimentão em ambiente protegido. Horticultura Brasileira, v.23, p.94-99, 2005

GUIMARÃES, C.M.; STONE， L.F.; NEVES, P. de C.F. Eficiência produtiva de cultivares de arroz com divergência fenotípica. Revista Brasileira de Engenharia Agrícola e Ambiental, v.12, p.465-470, 2008.

JANDEL. Jandel TBLCURVE: Table Curve 3.0: curve fitting software. Corte Madera: Jandel Scientific, 1992. 280p.

JAUER, A.; DUTRA, L.M.C.; ZABOT, L.; LUCCA FILHO, O.A.; LOSEKANN, M.E.; UHRY, D.; STEFANELO, C.; FARIAS, J.R.; LUDWIG, M.P. Análise de crescimento da cultivar de feijão Pérola em quatro densidades de semeadura. Revista da FZVA, v.10, p.1-12, 2003.

JOLLIFFE, P.A.; GAYE, M.-M. Dynamics of growth and yield component responses of bell peppers (Capsicum annuum L.) to row covers and population density. Scientia Horticulturae, v.62, p.153-164, 1995.

KAHN, B.A.; COOKSEY, J.R.; MOTES, J.E. Within-row spacing effects on traits of importance to mechanical harvest in paprika-type peppers. Scientia Horticulturae, v.69, p.31-39, 1997.

LÓPEZ-BELLIDO, F.J.; LÓPEZ-BELLIDO, L.; LÓPEZ-BELLIDO, R.J. Competition, growth and yield of faba bean (Vicia faba L.). European Journal of Agronomy, v.23, p.359-378, 2005.

MACHADO, A.Q.; ALVARENGA, M.A.R.; FLORENTINO, C.E.T. Produção de tomate italiano (saladete) sob diferentes densidades de plantio e sistemas de poda visando ao consumo in natura. Horticultura Brasileira, v.25, p.149-153, 2007.

MONTE, J.A.; PACHECO, A. de S.; CARVALHO, D. de F.; PIMENTEL, C. Influência do turno de rega no crescimento e produção do tomateiro no verão em Seropédica. Horticultura Brasileira, v.27, p.222-227, 2009.

MOTSENBOCKER, C.E. In-row plant spacing affects growth and yield of pepperoncini pepper. HortScience, v.31, p.198-200, 1996.

PEREIRA， F.H.F.; NOGUEIRA， I.C.C.; PEDROSA， J.F.; NEGREIROS, M.Z.; BEZERRA NETO, F. Poda da haste principal e densidade de cultivo na produção e qualidade de frutos em híbridos de melão. Horticultura Brasileira, v.21, p.192-197, 2003.

PÔRTO, D.R. de Q.; NEGREIROS, M.Z. de; MEDEIROS, J.F. de; GONDIM, A.R. de O.; BEZERRA NETO, F. Crescimento do melão 'Torreon' cultivado em diferentes coberturas de solo e lâminas de irrigação. Revista Caatinga, v.18, p.232-237, 2005.

RIBEIRO JÚNIOR, J.I. (Ed.). Análises estatísticas no SAEG. Viçosa: UFV, 2001. 301p

SANTOS, H.G. dos; JACOMINE, P.K.T.; ANJOS, L.H.C. dos; OLIVEIRA, V.A. de; OLIVEIRA, J.B. de; COELHO, M.R.; LUMBRERAS, J.F.; CUNHA, T.J.F. (Ed.). Sistema brasileiro de classificação de solos. 2.ed. Rio de Janeiro: Embrapa Solos, 2006. 306p. 
STRECK, N.A.; BURIOL, G.A.; ANDRIOLO, J.L.; SANDRI, M.A. Influência da densidade de plantas e da poda apical drástica na produtividade do tomateiro em estufa de plástico. Pesquisa Agropecuária Brasileira, v.33, p.1105-1112, 1998.
TURNER, A.D.; WIEN, H.C. Dry matter assimilation and partitioning in pepper cultivars differing in susceptibility to stress-induced bud and flower abscission. Annals of Botany, v.73, p. $617-622,1994$.

Recebido em 3 de março de 2009 e aprovado em 8 de janeiro de 2010 